\title{
A new stage of the nutrition transition in China
}

\author{
Shufa Du ${ }^{1,2}$, Bing Lu², Fengying Zhai ${ }^{1}$ and Barry M Popkin ${ }^{2, *}$ \\ ${ }^{1}$ Institute of Nutrition and Food Hygiene, Chinese Academy of Preventive Medicine, Beijing, People's Republic of \\ China: ${ }^{2}$ Department of Nutrition, University of North Carolina at Chapel Hill, 123 West Franklin Street, Chapel Hill, \\ NC 27516-3997, USA
}

\begin{abstract}
Objective: To fully explore the long-term shifts in the nutrition transition and the full implications of these changes in the Chinese diet.

Design: A descriptive, population-based study.

Setting: Data come from nationally representative surveys: the China Health and Nutrition Survey (1989-1997), the China National Nutrition Survey (1982 and 1992), the annual household consumption surveys of the State Statistical Bureau, and the Annual Death Report of China.

Results: During the first part of the major economic transformation in China (before 1985), cereal intake increased but decreased thereafter. There was also a long-term reduction of vegetable consumption that has now stabilised. Intake of animal foods increased slowly before 1979 and more quickly after the economic reforms occurred. While the total energy intake of residents has decreased, as has energy expenditure, large changes in the composition of energy have occurred. The overall proportion of energy from fat increased quickly, reaching an overall average of $27.3 \%$ and $32.8 \%$ for urban residents in 1997. Over a third of all Chinese adults and $60.1 \%$ of those in urban areas consumed over 30\% of their energy from fat in 1997. Large shifts towards increased inactivity at work and leisure occurred. These changes are linked with rapid increases of overweight, obesity and diet-related non-communicable diseases (DRNCDs) as well as total mortality for urban residents.

Conclusions: The long-term trend is a shift towards a high-fat, high-energy-density and low-fibre diet. The Chinese have entered a new stage of the nutrition transition.
\end{abstract}

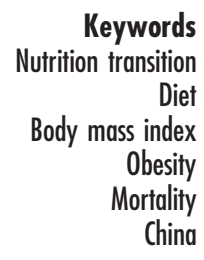

China represents one of the more rapidly developing countries in the world. In the past two decades, the annual growth rate of the gross domestic product (GDP) was more than $8 \%$, the highest rate in recent world history ${ }^{1}$. China has achieved remarkable economic progress and high levels of education, but a rapid evolution of the Chinese diet has accompanied these economic shifts and related social changes. A longer, more detailed history of the Chinese nutrition transition is available ${ }^{2}$.

The classic Chinese diet includes cereals and vegetables with few animal foods. It is a diet that many scholars consider most healthful when adequate levels of intake are achieved ${ }^{3}$. Earlier research by these authors has shown rapid changes in the diets and body composition of Chinese adults during the 1980-91 period ${ }^{4,5}$. As the classic eating pattern shifts, intakes of cereals and many lower-fat, mixed dishes are being replaced, animal foods are becoming popular, and the consumption of edible oils is increasing quickly. This shift in the composition of diet and corresponding body composition has been accompanied by many positive and some negative changes. Infectious diseases and hunger, important causes of death in the 1950s, no longer affect most of the population. Although malnutrition and nutrition deficiency diseases are still problems that should not be overlooked, the burden is shifting to diet-related, noncommunicable disease (DR-NCD) with a rapid increase in the prevalence of obesity. Fertility and mortality, particularly infant and child mortality, are declining; respiratory diseases are rapidly receding in importance; and life expectancy has reached high levels. Heart diseases, cerebrovascular diseases and cancer are now the major sources of mortality.

There are five periods of dietary pattern change in China that fit together to mark shifts in the stages of the nutrition transition in China ${ }^{6}$. This paper shows that China is transforming very rapidly from the pattern of the earliest, receding famine stage, to that of the present, DR-NCD stage. The first period was between 1949 and 1957, when food production was inadequate and low cereal consumption patterns existed. The second period was a sharp decrease in food consumption from 1957 to 1962 during the famine linked with The Great Leap Forward ${ }^{7}$. The third period, between 1962 and 1979, was one of a strong recovery. The fourth, or reform period, from 1979 to 1985 , came after the liberalisation of food production, when the annual economic growth rate was over 10\%. After this rapid growth, further economic improvement led to a shift in energy requirements and the structure of the Chinese diet shifted; this is the fifth period presented in Popkin 
et $a l .{ }^{4}$ (1993). This paper explores the long-term shifts in the nutrition transition through these stages and the full implications of these changes in the Chinese diet.

\section{Subjects and methods}

\section{Dietary data}

Data were obtained from three sources. First, data from the 1952 to 2000 annual household consumption surveys ${ }^{8}$ were used to analyse the long-term transitions in dietary and nutrition in China. The design of the surveys undertaken by the State Statistical Bureau (SSB) is similar to a longitudinal survey, but about $20 \%$ of households in the sampling communities would be changed each year ${ }^{8}$. Second, two rounds of the China National Nutrition Survey (CNNS) data (1982 and 1992) were used in this paper each from large nation-wide surveys?. From the third source, the China Health and Nutrition Survey (CHNS), rounds of the 1989-1997 data are used ${ }^{6,10}$. In both cases, dietary data were collected by a combination of the weighing method and three consecutive 24-hour recalls. CNNS and CHNS data are used for the short-term analyses.

\section{Physical activity data}

The CHNS collected detailed data on occupation, work character, labour force, work time and other items related to physical activities. Physical activity was classified into three categories: light, moderate and vigorous ${ }^{11}$. The ownership of television (TV) sets was also analysed to reflect the shift in physical activities.

\section{Antbropometric data}

Data from both CNNS and CHNS were used; both surveys measured height and weight ${ }^{12,13}$. The World Health Organization's (WHO) cut-off points for body mass index (BMI) were used to define underweight (BMI < $18.5 \mathrm{~kg} \mathrm{~m}^{-2}$ ) and overweight (BMI $\geq 25 \mathrm{~kg} \mathrm{~m}^{-2}$ ). Overweight and obesity (BMI $\geq 30 \mathrm{~kg} \mathrm{~m}^{-2}$ ) categories are combined for two reasons. The proportion of $\mathrm{BMI} \geq$ $30 \mathrm{~kg} \mathrm{~m}^{-2}$ was very low (only $1.5 \%$ in 1992) and a recent international group from the WHO-Pacific Region has recommended that a lower BMI cut-off for overweight and obesity of 23 and $25 \mathrm{~kg} \mathrm{~m}^{-2}$, respectively, should be used in Asia $^{14}$.

\section{Mortality and causes of death data}

These data came from the Annual Death Report from the Ministry of Health of China. Diseases are classified according to WHO's International Classification of Disease, Injuries, and Causes of Death, version 9 (ICD-9).

\section{Results}

\section{Food consumption pattern}

The shift in the Chinese diet follows a classic Westernisation pattern. The economic progress, linked in part to liberalisation of food production controls and the introduction of a free market for food and food products, is linked to these important shifts in diet ${ }^{15}$. This study focused on shifts in key, separate components of the Chinese diet.

\section{Cereals}

Long-term. There are really five different periods of change in the past. The first period was between 1949 and 1957 when food production was inadequate and low cereal consumption patterns existed. There is a lack of data on cereal consumption during the second period from 1957 to 1962, but there was a sharp decrease in food consumption during the famine linked with The Great Leap Forward ${ }^{7}$. Per capita intake of cereals increased steadily from $165 \mathrm{~kg}$ to $195 \mathrm{~kg}$ ( $1.8 \mathrm{~kg}$ annually) in the third period (1962-1979), one of strong recovery. During the fourth or reform period (1979-1985), after the liberalisation of food production when the annual economic growth rate was over 10\%, China began to import cereals. As a result, per capita intake of cereals increased by $60 \mathrm{~kg}$ within six years; $10 \mathrm{~kg}$ each year, or a $27.4 \mathrm{~g}$ increase each day. Further economic improvement led to a shift in energy requirements, the structure of the Chinese diet shifted, and cereal consumption has declined slowly since 1985; this is the fifth period ${ }^{4}$.

Short-term. Both CNNS and CHNS data show that the intake of cereals decreased considerably during the past two decades in both urban and rural areas and among all income groups. During the eight-year period from 1989 to 1997, the total mean intake of cereals decreased by 127 g person $^{-1}$ day $^{-1}$ (67 g person ${ }^{-1}$ day $^{-1}$ for urban resi-

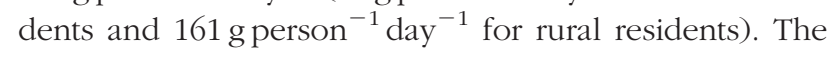
decrease in the low-income group was the highest (196 g person ${ }^{-1}$ day $^{-1}$ ) compared with their counterparts in middle- and high-income groups (86 and 85 g person $^{-1}$ day $^{-1}$, respectively).

The shift away from coarse grain consumption such as millet, sorghum and corn is a key component of this change. CHNS data show a decrease of 38 g person $^{-1}$ day $^{-1}$ in refined cereals between 1989 and 1997, but an even larger decrease in coarse cereal consumption of 89 g person $^{-1}$ day $^{-1}$. CNNS data show the intake of refined cereals in 1992 to be similar to that in 1982, but the intake of coarse cereals decreased by 59 g person $^{-1}$ day $^{-1}$.

\section{Vegetables and fruits}

Long-term. Urban residents' intake, which was slightly higher than rural residents', decreased steadily from 1983 to 1997 and stabilised thereafter. Among rural residents, there was a sharp decrease from 1992 to 1993, a smaller decline from 1993 to 1995, and then a slight increase. 
Short-term. CHNS data show that the total intake of vegetables decreased by 32 g person $^{-1}$ day $^{-1}$ between 1989 and 1997; the intake of vegetables of rural residents decreased by $52 \mathrm{~g}$ person $^{-1} \mathrm{day}^{-1}$.

In contrast, the intake of fruits, which are much more expensive than vegetables, showed an increase of 6.9 g person $^{-1}$ day $^{-1}$ from 1989 to 1997. Urban residents' intake of fruits in 1997 was 2.5 times that of 1989. Rural residents' intake of fruits increased by $1.8 \mathrm{~g}_{\text {person }}{ }^{-1}$ day $^{-1}$ during the same period.

As a whole, total intakes of vegetables and fruits decreased from $391.8 \mathrm{~g}_{\text {person }}{ }^{-1} \mathrm{day}^{-1}$ in 1989 to 366.7 g person $^{-1}$ day $^{-1}$ in 1997 . The largest decrease occurred in the low-income group, from 441.5 to $364.0 \mathrm{~g}_{\text {person }}{ }^{-1} \mathrm{day}^{-1}$, or $77.5 \mathrm{~g}_{\text {person }}{ }^{-1} \mathrm{day}^{-1}$.

\section{Animal foods}

Long-term. Per capita annual consumption of animal foods more than tripled from a very low consumption level of $11 \mathrm{~kg}$ in 1952 to $38 \mathrm{~kg}$ in 1992 . There was a slow rate of increase prior to 1979 but thereafter it was much higher. Intake increased by only $5.6 \mathrm{~kg}$ ( $0.2 \mathrm{~kg}$ annually) from 1952 to 1979 , while it increased by $21 \mathrm{~kg}$ (1.6 kg annually) between 1979 and 1992. Urban residents' annual intake increased to $65.3 \mathrm{~kg}$ person $^{-1}$ in 1999.

Short-term. Urban residents' daily intake of animal foods per capita in 1997 was higher than for rural residents (178.2 vs. $116.7 \mathrm{~g} p e r s o n^{-1} \mathrm{day}^{-1}$ ) and also showed a larger increase ( 46.7 vs. $36.8 \mathrm{~g}$ person $^{-1} \mathrm{day}^{-1}$ ) from 1989 to 1997 . The amount and growth of intake of animal foods were positively associated with income levels. Intake in the low-income group was 77.6 g person $^{-1}$ day $^{-1}$ in 1997 , an increase of $18.6 \mathrm{~g}$; while it was 123.2 and 19.6 g person $^{-1}$ day $^{-1}$ in the middle-income group; and 191.7 and $64.8 \mathrm{~g}$ person ${ }^{-1} \mathrm{day}^{-1}$ for the high-income group. The intake level and the increase in the highincome group were almost three times those in the lowincome group.

\section{Composition of energy and micronutrients in the diet}

\section{Long-term}

Trends of energy intake were similar to those of cereals. Total energy intake increased before 1985; then began to decrease. Total energy intake was $2270 \mathrm{kcal}(9.50 \mathrm{MJ})$ in $1952,2440 \mathrm{kcal}(10.21 \mathrm{MJ})$ in 1982 and $2328 \mathrm{kcal}(9.74 \mathrm{MJ})$ in 1992. Among the energy components, there was little change in the proportion of energy from protein, but the proportion of protein from animals increased considerably. Only $3.1 \%$ of protein came from animal foods in 1952 , which increased to $18.9 \%$ in 1992 . The intake of fat doubled (28.3 vs. $58.3 \mathrm{~g}$ ). Sources of energy changed remarkably: energy from fat increased twofold (11\% vs.
Table 1 Shifts in energy sources for 20- to 45 -year-old adults (China Health and Nutrition Survey 1989-1997)

\begin{tabular}{|c|c|c|c|c|c|c|c|c|}
\hline & \multicolumn{4}{|c|}{$\begin{array}{l}\text { Percentage } \\
\text { of energy } \\
\text { from fat }\end{array}$} & \multicolumn{4}{|c|}{$\begin{array}{c}\text { Percentage } \\
\text { of energy } \\
\text { from carbohydrates }\end{array}$} \\
\hline & 1989 & 1991 & 1993 & 1997 & 1989 & 1991 & 1993 & 1997 \\
\hline Urban & 21.4 & 29.7 & 32.0 & 32.8 & 65.8 & 58.0 & 55.0 & 53.3 \\
\hline Rural & 18.2 & 22.5 & 22.7 & 25.4 & 70.0 & 65.6 & 65.2 & 62.1 \\
\hline Low-income & 16.0 & 19.3 & 19.7 & 23.0 & 72.9 & 69.2 & 68.6 & 64.5 \\
\hline Middle-income & 20.3 & 25.2 & 25.5 & 27.1 & 67.5 & 62.6 & 62.2 & 60.3 \\
\hline High-income & 21.5 & 30.0 & 31.5 & 31.6 & 65.4 & 57.5 & 55.4 & 54.8 \\
\hline Total & 19.3 & 24.8 & 25.5 & 27.3 & 68.7 & 63.2 & 62.1 & 59.8 \\
\hline
\end{tabular}

$22 \%$ ), energy from carbohydrates decreased from $77 \%$ to $66 \%$, and energy from animal foods increased from $4.9 \%$ to $9.3 \%$.

\section{Short-term}

CHNS data show the shift away from carbohydrates to fat in the diet. Energy from carbohydrates for all residents (Table 1) decreased to 59.8\% in 1997 from 68.7\% in 1989 and to only $53.3 \%$ from $65.8 \%$ in 1989 among urban residents, the lowest for any group. Energy from fat increased sharply from $19.3 \%$ in 1989 to $27.3 \%$ in 1997. The shift towards a high-fat diet is shown more pointedly by examining those with low- and high-fat diets, and diets higher in animal fat, from 1989 to 1997 . The proportion of adults with a high-fat diet increased by 2.5 times (14.7\% vs. $38.5 \%$ ) within these eight years. The proportion of adult diets with a fat energy of less than 10\% declined considerably (18.4\% to $3.1 \%$ ) over this same eight-year period. Over $60 \%$ of urban residents consumed more than $30 \%$ of energy from fat in 1997.

\section{Physical activity}

Energy expenditure at work and the proportion of TV set ownership from 1989 to 1997 were used to measure changes in daily physical activities. Large changes in technology in the workplace and in leisure activities are linked with rapid declines in physical activity. Economic activities are shifting towards the service sector, particularly in urban areas ${ }^{16}$. The proportion of urban adults working in occupations where they participate in vigorous activity patterns has decreased, and increased where the activity pattern is light. In rural areas, however, there has been a shift towards increased physical activity linked to residents holding multiple jobs and more intensive effort. For rural women, there is a shift towards a larger proportion engaged in more energy-intensive work but there are also proportions where light effort is increasing. In contrast, the proportion of rural men engaged in light work effort has decreased slightly.

TV set ownership increased considerably during this eight-year period, especially in rural areas and among lower-income groups. In 1997, close to 90\% of Chinese 
households owned a TV set. Clearly, TV ownership represents a major, potential source of inactivity.

\section{Body composition}

There has been a profound increase in the body mass index distribution of Chinese adults, particularly at BMI levels from 23 to $30 \mathrm{~kg} \mathrm{~m}^{-2}$. Overweight and obesity were rare in 1982; only $3.5 \%$ of adults, aged $20-45$ years, had a BMI above $25 \mathrm{~kg} \mathrm{~m}^{-2}$ and only $0.2 \%$ were classified as obese. These rates increased fourfold to $14.1 \%$ and $1.3 \%$, respectively, in 1997. The prevalence was much higher in urban areas compared with rural areas (20.9\% vs. $14.2 \%)$, and this was especially true in large cities. In 1992, more than $40 \%$ of urban residents in Beijing were overweight and obese, which would be a serious public health problem ${ }^{9}$. In the past 15 years, there has been an increase of almost one percentage point per year (0.93) in the prevalence rate, equal to an additional 12 million overweight and obese cases each year.

At the same time, there is still a meaningful proportion of adults with low BMI who face chronic undernutrition (Table 2). CHNS and CNNS data show that this proportion decreased by 0.4 percentage points yearly during the period 1982-1992, and by 0.2 percentage points yearly between 1992 and 1997.

\section{Morbidity}

CHNS blood pressure data show a modest increase in hypertension between 1991 and 1997 among adults aged 30-65 years. Hypertension is greater among males and urban residents, which is not surprising given the greater obesity found in urban areas. Interestingly, the prevalence of hypertension in males in urban areas decreased slightly (not statistically significant) from 1991 to 1997, while it increased among all other groups, especially in rural males.

\section{Mortality of degenerative chronic diseases}

The overall death rate decreased between 1974 and 1984, there was no major clear reduction from 1984 to 1990 , and a rise since then in urban areas. It increased by 34.7 per

Table 2 Trends of BMI distribution for 20- to 45-year-old adults (China Health and Nutrition Survey 1989-1997)

\begin{tabular}{|c|c|c|c|c|c|c|c|c|}
\hline & \multicolumn{8}{|c|}{ Distribution (\%) } \\
\hline & \multicolumn{4}{|c|}{$\mathrm{BMI}<18.5 \mathrm{~kg} \mathrm{~m}^{-2}$} & \multicolumn{4}{|c|}{$\mathrm{BMI} \geq 25 \mathrm{~kg} \mathrm{~m}^{-2}$} \\
\hline & 1989 & 1991 & 1993 & 1997 & 1989 & 1991 & 1993 & 1997 \\
\hline Urban & 7.8 & 7.8 & 7.7 & 6.2 & 10.6 & 12.1 & 12.7 & 18.7 \\
\hline Rural & 8.3 & 8.4 & 7.3 & 5.6 & 8.4 & 9.9 & 10.2 & 13.7 \\
\hline Male & 7.4 & 7.3 & 6.2 & 5.5 & 6.4 & 8.2 & 9.1 & 14.5 \\
\hline Female & 8.7 & 9.1 & 8.6 & 6 & 11.5 & 12.7 & 12.6 & 16.2 \\
\hline Low-income & 6.9 & 9.8 & 7.4 & 6 & 6.3 & 6.6 & 9.5 & 10.9 \\
\hline Middle-income & 10 & 8.1 & 7.7 & 6.3 & 9.1 & 11.7 & 10 & 14.7 \\
\hline High-income & 7.5 & 6.7 & 7.2 & 4.5 & 10.7 & 13.6 & 13.5 & 19.6 \\
\hline Total & 8.1 & 8.2 & 7.5 & 5.8 & 10.3 & 10.6 & 10.9 & 15.4 \\
\hline
\end{tabular}

100000 during this latter period (Fig. 1) ${ }^{17}$. This shift is noteworthy, as it seems to be concurrent with the increase in DR-NCDs related to the circulatory system and cancer. The 1999 specific mortality of infection and parasite diseases in rural areas, for example, was one-seventh of the 1974 rate ( 58.2 vs. 8.0 per 100000 ), but the mortality of diabetes in urban areas increased fivefold in 1999 compared with 1974 (15.4 vs. 3.4 per 100 000).

\section{Discussion}

In the half-century since Chinese independence, there have been five major periods related to the stages of the nutrition transition. The country was transformed from one facing famine and extreme food shortages to one where the food supply addressed basic needs; food intake of key food types (cereals, vegetables, animal foods) as well as total energy intake increased. Continuing the shift towards a reduction of malnutrition between 1985 and 1990, total energy began to decrease, and food diversity and animal food intake increased considerably. After 1990, China entered a later stage of the transition as obesity began to increase, energy density of the diet increased considerably, and cereal intake decreased considerably. DR-NCDs began to increase rapidly.

\section{What is the basis for stating a new stage of the nutrition transition was reached?}

First, the overall 1999 death rate among urban residents increased to a higher rate than in the early 1970s primarily from DR-NCDs such as cardiovascular diseases, diabetes and cancers. Mortality rates of rural residents are still improving (lowering), but we expect these rates will also shift upwards in the next several decades. Farmers have become richer in many regions of the country and the rural diet is following the same shift towards animal products that urban areas followed (i.e. reduced carbohydrate and increased edible oil and total fat). Adult obesity in rural areas is beginning to increase. Cancer and cardiovascular disease will soon become the major causes of mortality in rural China.

Second, China is facing simultaneous challenges of malnutrition and overnutrition. In past decades, the government tried its best to solve the malnutrition problem and made great progress. However, the prevalence of malnutrition is still very high: $35 \%$ of pre-school children were stunted; $20 \%$ of pre-school children, $22 \%$ of school children and adolescents, and $8 \%$ of adults were suffering from undernutrition ${ }^{18}$. On the other hand, the prevalence of overweight and obesity has risen to a relatively high degree. Other studies have shown large increases in overweight among pre-school children, older children and teenagers ${ }^{19}$. For example, $15 \%$ (28\% in urban areas) of children aged 2-6 years and 8\% (12\% in urban areas, 11 times that of 15 years ago) of children and adolescents aged 7-17 years were overweight and obese, based on the 


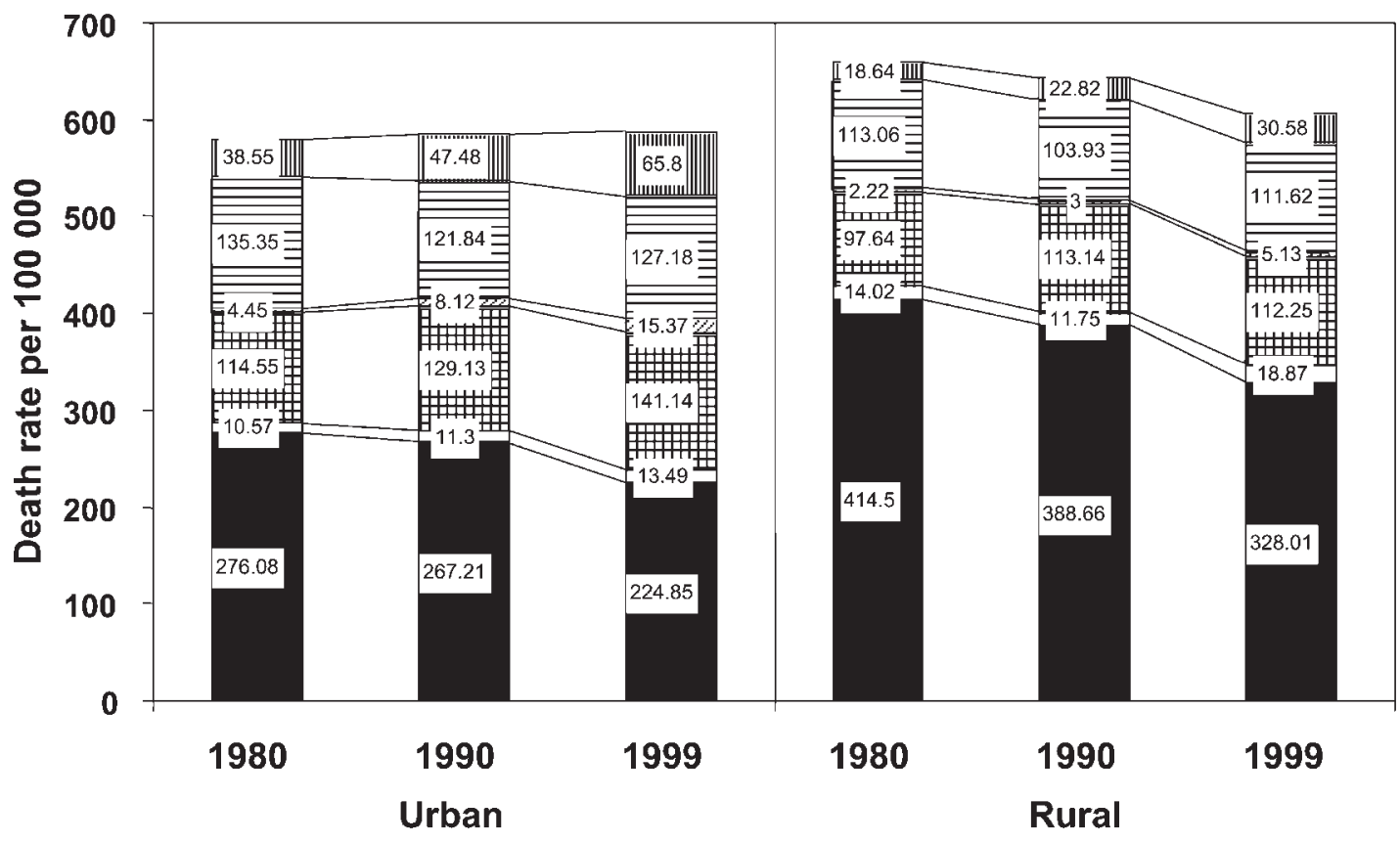

DOther diseases $\square$ Hypertensive cardiopathy $\boxplus$ Cancers \&Diabetes ECerebrovascular $\mathbf{W C H D}$

Fig. 1 Trends in the causes of mortality in China, 1980-1999 (CHD - coronary heart disease). Source: Ministry of Health of China ${ }^{17}$

cut-off points of BMI for overweight and obesity from the International Obesity Task Force (IOTF) ${ }^{18}$.

The research by Doak et $a l^{20}$ highlights this shift in the distribution of under- and overnutrition in a different way. Their research identified households in which overweight and underweight coexist, and explored causative household levels. In China, the prevalence of such households was $8 \%$.

Third, marked shifts in the Chinese diet have been shown. Unlike other East Asian countries such as South Korea (which has actively promoted its traditional diets), China seems to be rapidly relinquishing its traditional diet. The level of fat intake in South Korea is even lower than in China, although China's gross national product (GNP) was less than 1/14 of the GNP in South Korea in 1996. Starting in the 1990s, people in China obtained more than $20 \%$ of energy from fat while South Koreans consumed less than $20 \%$ of energy from fat in $1995^{21}$. Edible oil intake increases unabated in China, as does the intake of other animal products ${ }^{22}$.

Also, there has recently been a rapid increase in food consumption from away-from-home sources. Popkin et $a l .{ }^{10}$ have shown the energy consumed at restaurants and stalls in China increased from $0.4 \%$ in 1989 to over $7.4 \%$ in 1997. Some scholars feel that increased awayfrom-home food consumption is a contributing factor to increased overweight and obesity ${ }^{23}$.

\section{Acknowledgements}

The authors thank Ms Frances L Dancy for her administrative assistance, Bill shapbell for editing assistance, Tom Swasey for his work on the graphics, and Ms Zhihong Wang and Ms Hongfei Hao for assistance in data collection. Financial assistance for this research has come from the US National Institutes of Health (NIH) (R01-HD30880 and R01-HD38700) and the Fogarty International Center, NIH, National Science Foundation (grant \#37486) (for Shufa Du and Bing Lu).

\section{References}

1 World Bank. World Development Indicators 2001. Washington, DC: World Bank, 2001.

2 Du S, Lu B, Zhai F, Popkin BM. The nutrition transition in China: a new stage of the Chinese diet. In: Caballero B, Popkin B, eds. The Nutrition Transition: Diet-related Diseases in the Developing World. London: Academic Press [in press].

3 Campbell TC, Parpia B, Chen J. Diet, lifestyle, and the etiology of coronary artery disease: the Cornell China study. Am.J. Cardiol. 1998; 82: 18-21T.

4 Popkin BM, Ge K, Zhai F, Guo X, Ma H, Zohoori N. The nutrition transition in China: a cross-sectional analysis. Eur. J. Clin. Nutr. 1993; 47: 333-46.

5 Popkin BM, Paeratakul S, Zhai F, Ge K. Body weight patterns among the Chinese: results from the 1989 and 1991 China Health and Nutrition Surveys. Am. J. Public Health 1995; 85(5): 690-4.

6 Popkin BM. Nutritional patterns and transitions. Popul. Dev. Rev. 1993; 19(1): 138-57.

7 Piazza A. Food Consumption and Nutritional Status in the PRC. Westview Special Studies on China. Boulder, CO: Westview Press, 1986.

8 State Statistical Bureau (SSB). China Statistical Yearbook 2000. Beijing: China Statistics Press, 2001.

9 Ge K. Summary of the Third National Nutrition Survey. J. Hygiene Res. 1996; 25(Suppl): 1-8 [in Chinese]. 
10 Popkin BM, Lu B, Zhai F. Understanding the nutrition transition: measuring rapid dietary changes in transitional countries. Public Health Nutr. 2002 [in press].

11 Bell C, Ge K, Popkin BM. Weight gain and its predictors in Chinese adults. Int. J. Obes. Relat. Metab. Disord. 2001; 25: 1079-86.

12 Du S, Zhai F, Ge K. Distributions of body mass index in Chinese adults, aged 20-60 years. J. Hygiene Res. 2001 30: 339-42 [in Chinese].

13 Ge K, Zhai F, Yan H, eds. The Dietary and Nutritional Status of Chinese Population (1992 National Nutrition Survey). Beijing: People's Medical Publishing House, 1996.

14 Inoue S, Zimmet P. The Asia-Pacific perspective: redefining obesity and its treatment. Sydney: Health Communications Australia Pty Ltd, 2000.

15 Guo X, Popkin BM, Mroz TA, Zhai F. Food price policy can favorably alter macronutrient intake in China. J. Nutr. 1999; 129: 994-1001.

16 Popkin BM. The nutrition transition and its health implications in lower income countries. Public Health Nutr. 1998; 1: 5-21.
17 Ministry of Health. Annual Statistical Reports of Death, Injuries and Causes of Death in China, 1979-2000. Beijing: Ministry of Health, 2000.

18 Du S, Lu B, Wang Z, Zhai F, Popkin BM. Transition of dietary pattern in China. J. Hygiene Res. 2001; 30: 221-5.

19 Du S. Growth and development of children and adolescents of 0-18 years old. In: Ge K, Zhai F, eds. The Dietary and Nutritional Status of Chinese Population - Children and Adolescents (1992 National Nutrition Survey). Vol. 2. Beijing: People's Medical Publishing House, 1999; 12-34.

20 Doak C, Adair L, Monteiro C, Popkin BM. Overweight and underweight co-exists in Brazil, China, and Russia. J. Nutr. 2000; 130: 2965-80.

21 Kim S, Moon S, Popkin BM. The nutrition transition in South Korea. Am. J. Clin. Nutr. 2000; 71: 44-53.

22 Drewnowski A, Popkin BM. The nutrition transition: new trends in the global diet. Nutr. Rev. 1997; 55(2): 31-43.

23 Binkley JK, Eales J, Jekanowski M. The relation between dietary change and rising obesity. Int. J. Obes. Relat. Metab. Disord. 2000; 24(8): 1032-9. 